\title{
REDE DE FLUXO DE CUSTO MÍNIMO DOS GRÃOS DE SOJA DO VETOR CENTRO-SUDESTE DO BRASIL PARA A EXPORTAÇÃO
}

\author{
Dermeval Martins Borges Júnior \\ Universidade Federal de Uberlândia \\ dermevaljr14@hotmail.com \\ Kleber Carlos Ribeiro Pinto \\ Universidade Federal de Uberlândia \\ kleber@ufu.br
}

\begin{abstract}
Resumo
Este trabalho tem o objetivo de identificar a rede de fluxo ótima para a exportação do grão de soja produzido na região geográfica do Vetor Logístico Centro-Sudeste do Brasil, considerando a infraestrutura logística existente em 2012. A produção e a exportação do grão de soja são importantes para economia brasileira. Os parâmetros processados são dados secundários de organizações governamentais e o procedimento de estudo recorre à Programação Linear. Foram consideradas dez combinações de modais de transportes em uma rede capacitada formada por quarenta e sete origens e três destinos. Um modelo matemático para minimizar os custos da rede foi construído e resolvido com o uso da linguagem de modelagem GAMS. Os resultados indicaram que o porto de Santos deve ser o principal destino para o grão produzido nas regiões do Triângulo Mineiro, sudoeste de Minas Gerais, sul de Goiás, São Paulo, e parte dos estados do Mato Grosso do Sul e Mato Grosso e a produção do norte do Paraná deve ir para o porto de Paranaguá. Devido às limitações de capacidade das alternativas de transporte, e em particular da hidrovia no período sazonal da seca, o resultado ótimo indica que $57 \%$ do volume exportado seriam direcionados aos portos exclusivamente pelo transporte rodoviário e $43 \%$, de alguma forma, passariam pela ferrovia.

Palavras-Chaves: programação linear; custos de transporte; logística da soja.
\end{abstract}

\section{Abstract}

This work aims to identify the optimal flow network for the export of soybeans produced in the geographical region of the Logistic Vector Center-Southeast of Brazil, considering the existing logistics infrastructure in 2012. The production and the exportation of grain soy are important to the Brazilian economy. The processed parameters are secondary data from government organizations and the study procedure uses the Linear Programming. Ten combinations of transport modes were considered in a capable network of forty-seven origins and three destinations. A mathematical model to minimize the cost of the network was constructed and solved using the GAMS modeling language. The results indicated that the port of Santos should be the main destination for the grain produced in the regions of Triangulo Mineiro, west of Minas Gerais, south of Goiás, São Paulo, and some of the states of Mato Grosso do Sul and Mato Grosso and the production of northern Paraná should go to the port of Paranaguá. Because of the limited capacity of transportation alternatives, particularly the waterway in the seasonal period of drought, the great result indicates that $57 \%$ of the exported volume should go to ports exclusively from road transport and $43 \%$ in some way, should go through railroad.

Keywords: $\quad$ linear programming; transportation costs; soybean logistics. 


\section{INTRODUÇÃO}

O transporte da soja em grão para a exportação constitui-se em um dos principais desafios da logística nacional e representa um obstáculo para a sua competitividade no mercado internacional. O fluxo entre o interior do país e os portos marítimos é feito principalmente pelo modal rodoviário, com custos variáveis mais elevados que o ferroviário e o hidroviário. A soja brasileira é produzida no campo com elevada produtividade e baixo custo, mas para chegar aos portos, precisa passar por uma rede logística com pequena participação dos modais ferroviário e hidroviário e por rodovias desgastadas que provocam perdas de grãos.

Conforme aponta o estudo realizado pelo Departamento de Relações Internacionais e Comércio Exterior - DEREX da Fiesp (2014), entre janeiro e novembro de 2014 as exportações da oleaginosa corresponderam a $11,2 \%$ do total de todos os produtos que deixaram o país com destino ao mercado exterior, o que equivale a US\$23,4 bilhões. A soja é o produto agrícola brasileiro mais exportado e a estimativa de produção do grão para safra 2014/15 é de 95,8 milhões de toneladas (CONAB, 2015).

Este trabalho analisa o fluxo das exportações da soja desde as regiões produtoras que estão sob influência do Vetor Centro-Sudeste, delineado pelo Plano Nacional de Logística e Transporte - PNLT do Ministério dos Transportes (2007), que corresponde à totalidade dos estados de São Paulo e Mato Grosso do Sul, o Triângulo Mineiro, o sudoeste de Minas Gerais, o sul de Goiás, o sul do Mato Grosso e norte do Paraná, até os portos de Santos (SP), Paranaguá (PR) e São Francisco do Sul (SC). As regiões sob influência do Vetor CentroSudeste produziram em 2012 58,3\% da soja de todo o país (IBGE, 2012). As alternativas de transporte contempladas consideram as disponibilidades atuais dos modais rodoviário, ferroviário, hidroviário e o transporte multimodal.

A estrutura deste artigo consiste em: uma revisão da literatura, abrangendo um breve histórico da produção e exportação da soja brasileira; os modais de transporte e a logística nacional; uma exposição sobre os problemas de programação linear, incluindo o método Simplex e a Linguagem de Modelagem GAMS (General Algebraic Modeling System) desenvolvido por Brooke e outros (1992); as considerações metodológicas, que envolvem os modelos matemáticos, e; as análises dos resultados obtidos com a resolução do modelo.

\section{REVISÃO DA LITERATURA}

\subsection{SOJA: ORIGENS E EXPANSÃO DA PRODUÇÃO NO BRASIL}

A introdução da soja nas Américas se deu apenas no século XIX, e consolidou como principal cultura do agronegócio brasileiro a partir de 1970. Atualmente, a soja é a principal oleaginosa cultivada no mundo, tendo como principais países produtores: Estados Unidos da América, Brasil, Argentina e China que representam cerca de $90 \%$ da produção mundial (PONTES; CARMO; PORTO, 2009).

A produção de soja está entre as atividades econômicas com crescimento mais expressivo nas últimas décadas. A consolidação da oleaginosa como fonte importante de proteína vegetal e a disponibilidade de tecnologias viabilizaram a expansão do cultivo do grão para diversas regiões do mundo (HIRAKURI; LAZZAROTTO, 2011).

O complexo da soja, que representa o grão, o farelo, o óleo de soja e seus derivados, faz da cultura, a principal produção agrícola do país, em termos de volume e geração de renda (LAVORENTE, 2011).

No Brasil a produção evoluiu dos Estados da região sul para Goiás, Mato Grosso, sul da Bahia e oeste de Minas Gerais. Sua expansão é em função das condições propícias de solo, clima e latitude para o desenvolvimento da cultura. Geralmente o cultivo da soja se dá sob o regime de rotação de culturas com outros vegetais, como trigo e milho, e o plantio é feito 
desde o final de setembro até fevereiro e a colheita, de janeiro até junho, dependendo da região geográfica (CONAB, 2015).

Em 2012 foram produzidas 65,8 milhões de toneladas, sendo que a região CentroOeste realizou 35 milhões e o Vetor Centro-Sudeste produziu 58,3\% do total do país, segundo os dados compilados da Pesquisa de Produção Agrícola Municipal (IBGE, 2012).

\subsection{EXPORTAÇÃO DA SOJA BRASILEIRA}

As exportações de grãos de soja entre 1990 e 2005 tiveram taxa anual média de crescimento de $14,8 \%$. A participação da China como compradora e a desvalorização cambial do Real em 1999 contribuíram para isso. Os principais importadores são China, Japão e países da União Européia, com ênfase para Holanda, Alemanha e Espanha. (LAVORENTE, 2011; CASSUCE; SANTOS, 2005; BAHIA et al., 2007).

No ano de 2013, o Brasil exportou 42,8 milhões de toneladas de soja em grãos, equivalente a 22,8 bilhões de dólares. As exportações de soja consideradas neste trabalho são as ocorridas através dos portos de Santos, Paranaguá e São Francisco do Sul (S. Fco. Sul). Em 2013, o porto de Santos foi responsável por aproximadamente 30\% do total de exportações anuais de grãos de soja no país, seguido pelos portos de Paranaguá e São Francisco do Sul, com $18 \%$ e $9,4 \%$, respectivamente (MDIC, 2013).

As regiões produtoras sob influência do Vetor Centro-Sudeste participaram com $51,9 \%$ de todas as exportações do grão, segundo os dados compilados do Sistema AliceWeb Análise das Informações de Comércio Exterior (MDIC, 2013).

O Brasil não desenvolveu a sua logística de armazenamento e transporte de commodities ao ritmo da demanda, o que acarreta perdas aos produtores, que são obrigados a vender seus produtos por preços baixos. A problemática central refere ao transporte excessivo em rodovias, com custos elevados e filas (ROSA; MAKIYA, 2011).

\subsection{OS MODAIS DE TRANSPORTE E A LOGÍSTICA NACIONAL}

O Brasil possui um gargalo logístico para a exportação das commodities que reduz as suas competitividades no mercado internacional. Popularmente chamado de "Custo Brasil", a carga tributária e as ineficiências do transporte e dos portos impõem altos custos e perdas (HIRAKURI; LAZZAROTTO, 2011).

O setor de transporte é fundamental para o desenvolvimento da economia de um país, pois viabiliza o funcionamento dos outros setores da economia. No caso do Brasil, a atual matriz de transporte de cargas, com ampla participação do transporte rodoviário, provoca perda de competitividade para as empresas nacionais devido ao elevado custo operacional, limitando o desenvolvimento do país. A carência de planejamento e de investimentos em infraestrutura na área acarreta a incapacidade do setor acompanhar a demanda, havendo o risco de ocorrer um colapso das operações logísticas (REIS et al., 2008).

O modal rodoviário é caracterizado pelos baixos custos fixos e elevados custos variáveis, que permite flexibilidade, mas por possuir veículos de menor escala que trens e chatas, é o mais caro para cargas commoditizadas, como a soja. As más condições das rodovias do Brasil também provocam perdas de grãos durante o transporte, cerca de 0,3\% ficam às margens das estradas (LAVORENTE, 2011; SILVA; MARUJO, 2012).

Enquanto o modal rodoviário, mais utilizado no Brasil, conta com 1,72 milhões de quilômetros $(\mathrm{km})$ pavimentados conforme dados do DNIT (2014), o modal ferroviário, o segundo mais utilizado no Brasil para o transporte de cargas, possui 28,5 mil km. O modal ferroviário é o mais indicado para o transporte da soja, mas o Brasil não foi, nas últimas décadas, um grande incentivador desse tipo de modal, por isso a capacidade não é suficiente para escoar toda a produção (SILVA; MARUJO, 2012; PINHEIRO; CAIXETA FILHO, 2010).

O modal hidroviário é o terceiro modal mais utilizado para o transporte de cargas no Brasil, com 16 hidrovias e 20 portos fluviais, mas quantidade insuficiente de eclusas, 
restrições com relação ao calado das embarcações, falta de integração com outros modais e inconsistência na oferta de barcaças impedem o uso desse pontencial. (SILVA; MARUJO, 2012; PONTES; CARMO; PORTO, 2009).

Para obter a máxima vantagem possível dos diferentes modais disponíveis, a intermodalidade se constitui como uma opção mais barata para o escoamento da produção de soja. Os principais benefícios da multimodalidade estão no melhor aproveitamento da infraestrutura das redes, na redução de custos, consumo energético e no tráfego. (SILVA; MARUJO, 2012; AMARAL; ALMEIDA; MORABITO, 2012).

Quando se trata de commodities, a percepção generalizada é de que há necessidade de investimentos em infraestrutura, contudo, enquanto as infraestruturas modais de transporte ferroviário e hidroviário não forem aprimoradas, o rodoviário continua participando de maneira significativa na rede de fluxo da soja (OJIMA, 2007; PEIXOTO; PINTO, 2012).

A soja, produto de baixo valor agregado sofre grandes impactos dos custos logísticos, podendo chegar a 34\% do valor do produto EMBRAPA (2008).

\subsection{ProgramaÇÃo Linear: O MÉTOdo SimpleX E O SISTEMa GAMS}

A programação linear (P.L) consiste em métodos determinísticos diretos otimizantes que são aplicados a problemas restritos de otimização e auxiliam o processo de tomada de decisão sobre problemas diversos, pois indicam soluções ótimas aos gestores responsáveis pelo planejamento nos níveis estratégico, tático e operacional, inclusive nas organizações que se preocupam com os transportes (PINTO, 2005; ANDRADE, 2009).

Este estudo apresenta um problema de programação linear de transporte, que é modelado e resolvido com a Linguagem de Modelagem GAMS, o qual considera o método simplex desenvolvido por Dantzig (1951). Esse tipo de problema busca identificar a quantidade de determinado produto que deve ser enviada das origens até os destinos, de forma que se possa minimizar o custo total envolvido no processo de distribuição desse produto (ANDRADE, 2009).

A programação linear exige a obtenção de um conjunto de dados, denominados 'parâmetros', referentes ao problema real a ser resolvido para que seja possível elaborar o modelo matemático linear corresponde ao problema (PPL), são os coeficientes das 'variáveis de decisão' e as 'limitações' de recursos. O modelo matemático representa a realidade de maneira simplificada e é elaborado com o objetivo de encontrar a solução ótima (PINTO, 2005; CAIXETA FILHO, 2001).

O primeiro passo na elaboração do modelo matemático corresponde à identificação das incógnitas do problema, as variáveis de decisão. Em seguida, ocorre a elaboração do modelo, consistindo em função objetivo e do conjunto de restrições (HILLIER; LIEBERMAN, 2006).

A solução dos PPL requer o método Simplex que, desenvolvido por George Dantzig em 1947, consiste em um algoritmo iterativo que se desenvolve até chegar ao ótimo. Há décadas os cientistas adeptos da matemática vêm desenvolvendo ferramentas computacionais que dão solução aos problemas algébricos de forma rápida. Um projeto de pesquisa iniciado em 1976 no Banco Mundial, para dar solução aos problemas de otimização, teve sua conclusão em 1988 por Brooke e outros, resultando na Linguagem de Modelagem GAMS General Algebraic Modeling System (HILLIER; LIEBERMAN, 2006; PINTO, 2005).

\section{PROCEDIMENTOS E MÉTODOS}

Neste trabalho, para encontrar a rede de fluxo de mínimo custo da soja para a exportação, foi empregado o sistema GAMS (General Algebraic Modeling System), proposto por Brooke e outros (1992). A coleta de dados secundários tem origem no relatório da Pesquisa de Produção Agrícola Municipal de 2012 do IBGE (2012), donde foram obtidas as quantidades de soja produzidas por município, e no Sistema Alice MDIC (2013), donde foram 
obtidas as quantidades exportadas, por estado e por porto, no ano de 2013

Foram contemplados no estudo, as regiões produtoras que estão sob a influência do Vetor Centro-Sudeste proposto no Plano Nacional de Logística e Transporte - PNLT do Ministério dos Transportes (2007), que corresponde à totalidade dos estados de São Paulo e Mato Grosso do Sul, Triângulo Mineiro e sudoeste de Minas Gerais, sul de Goiás, sul do Mato Grosso e norte do Paraná e os portos de: Santos (SP), São Francisco do Sul (SC), Paranaguá (PR). Os 806 municípios produtores desse vetor foram agrupados em centróides que representam uma agregação de municípios próximos suficientes para ajuntar em torno de meio milhão de toneladas de grãos anualmente, o que gerou 47 centróides.

$\mathrm{O}$ custo de transporte foi representado pelo frete cobrado entre os centróides e os portos por meio dos modais rodoviário, ferroviário, hidroviário e suas respectivas combinações. Assim para calcular os valores dos fretes foram utilizadas as estimativas de frete em reais por tonelada de soja a cada quilômetro percorrido ( $\$$ \$t.km) nos diversos modais e ou combinações, oferecidas pelo Laboratório de Transportes e Logística da Universidade Federal de Santa Catarina em relatório da Agência Nacional de Transportes Aquaviários - ANTAQ (2013). Para compor o cálculo dos fretes, foram consideradas: as distâncias entre os centróides e os portos, através do site Google Maps (2014) no caso de rodovias; a Pesquisa de Ferrovias da Confederação Nacional do Transporte - CNT (2011) no caso de ferrovias, e; o relatório de Transporte de Cargas na Hidrovia Paraná-Tietê 2010 da ANTAQ (2010) no caso das hidrovias.

No que tange ao problema de transporte, que visa o custo mínimo para a rede -47 centróides e 3 portos. As variáveis de decisão representam as quantidades a serem alocadas nos trechos que ligam os centróides aos portos, considerando os diferentes modais e ou combinações.

A função objetivo do problema representa o custo total da rede, que deve ser minimizada:

$$
Z=\sum_{i=1}^{47} \sum_{(j k)=1}^{10} C_{i,(j k)} \cdot X_{i(j k)} \rightarrow \text { Min! }
$$

Sendo:

$Z=$ o custo total da rede de fluxo da soja para a exportação;

$i=$ representa as origens produtoras, que varia de 1 a 47 (centróides);

$j k=$ varia de 1 a 10 e representa os modais e ou combinações possíveis para os 3 portos;

$C_{i, j k)}=$ o custo de transportar uma tonelada de soja entre a origem $(i)$ e o porto $(j)$ pelo modal e ou combinação de modal $(k)$, com notação $(j k)$;

$X_{i, j k)}=$ a quantidade em toneladas a serem transportadas entre a origem (i) e o porto (j) pelo

modal e ou combinação de modal $(k)$, com notação $(j k)$.

As restrições de oferta do modelo indicam que a soma das quantidades produzidas em cada uma das origens e destinadas aos portos não podem ser maior que a produção total da região produtora:

Sendo:

$$
\sum_{(j k)=1}^{10} X_{i,(j k)} \leq a_{i}
$$

$X_{i, j k)}=$ a quantidade em tonelada a ser transportada entre a origem $(i)$ e o porto $(j)$ pelo modal e ou combinação de modal $(k)$, com notação $(j k)$.

$a_{i}=$ produção de soja em tonelada em determinada origem - centróide $(i)$.

As restrições de demanda do modelo indicam que a soma das quantidades produzidas em cada origem e destinadas a cada porto através de uma combinação de modais precisa atender à respectiva demanda: 
Sendo:

$$
\sum_{i=1}^{47} X_{i(j k)} \geq b_{(j k)}
$$

$X_{i, j k)}=$ quantidade em toneladas a serem transportadas entre a origem $(i)$ e o porto $(j)$ pelo modal e ou combinação de modal $(k)$, com notação $(j k)$.

$b_{(j k)}=$ quantidade demandada em toneladas em determinado porto $(j)$ pelo modal e ou combinação de modal $(k)$, com notação por $(j k)$.

No modelo matemático, as origens (i) representam a produção dos centróides em 2012, a partir da compilação de dados oficiais do Instituto Brasileiro de Geografia e Estatística (IBGE, 2012), resultando em quarenta e sete pontos geográficos. Quanto aos destinos $(j)$ vinculados aos modais e ou combinações $(k)$, com notação $(j k)$, as quantidades seguem as respectivas exportações do trimestre crítico através dos portos analisados, observadas as capacidades dos modais e ou combinações de modal. Os dados referentes à exportação da soja disponibilizados pelo MDIC (2013) correspondem a cada unidade federativa, mas para chegar aos números por centróides, foram usadas as proporções das exportações por município do MDIC (2013) ponderadas à produção indicada pela Pesquisa de Produção Municipal do IBGE (2012).

Para cada modal de transporte ou combinação de modais $(\mathrm{k})$ foi necessário determinar o respectivo limite de capacidade de transporte: (1) no caso do modal ferroviário, foram consideradas como limites, as quantidades movimentadas de soja apontadas em CNT (2013) em cada par de origem destino; (2) as capacidades das hidrovias foram determinadas pelos volumes de soja indicados no estudo da Agência Nacional de Transporte Aquaviário ANTAQ (2012), e; (3) A capacidade do modal rodoviário foi definida como suficiente para completar toda a demanda requerida pelos portos de exportação, não representando limitação. No caso das combinações modais disponíveis, as quantidades destinadas aos portos de Paranaguá e São Francisco do Sul não admitem a possibilidade de transporte hidroviário em nenhuma das possíveis combinações de acesso entre regiões centróides e os portos, por isso as combinações modais são dez: Santos-rodoviário, Santos-ferroviário, Santos-rodo-ferroviário, Santos-rodo-hidro-ferrovário, Paranaguá-rodoviário, Paranaguá-ferroviário, Paranaguá-rodoferroviário, São Francisco-rodoviário, São Francisco-ferroviário e São Francisco-rodoferroviário.

Foi considerado que as exportações procedem dois meses após a colheita do grão, em razão das operações de transporte entre o campo e armazenagem local, secagem, armazenagem do grão seco e deslocamento até o porto. Assim, como a produção ocorre nos meses de fevereiro, março e abril, o período crítico (de pico) das exportações de soja no ano de 2013 ocorreu nos meses de abril, maio e junho, o que também serviu para delimitar a capacidade dos modais de transporte no período de três meses

\section{RESULTADOS E DISCUSSÃO}

A partir da resolução do modelo matemático, os resultados indicaram que para um trimestre, o custo mínimo total da rede de fluxo do transporte da soja para a exportação, o qual considera, no transporte intermodal, o desembolso do embarcador com as operações nos terminais intermodais e o seguro da carga, é de aproximadamente $\mathrm{R} \$ 909,8$ milhões. O volume da produção de soja nos centróides, de 19,8 milhões de toneladas e as exportações de 12,3 milhões mostram que o excedente de produção de 7,5 milhões atende à demanda doméstica ou à exportação por outros portos.

O volume de exportação anual de soja em 2013 pelos portos de Santos, Paranaguá e São Francisco do Sul corresponde a $57,4 \%$ do total exportado nesse mesmo ano. Contudo, considerando apenas o período de pico, que representa o trimestre analisado neste trabalho, o volume de exportações equivale a $62,3 \%$ do total. Assim, as exportações pelos portos de 
Santos, Paranaguá e São Francisco do Sul são mais acentuadas no trimestre de pico em comparação ao ano todo.

Na região do Triângulo Mineiro e sudoeste de Minas Gerais a solução ótima indicou que toda a soja produzida no trimestre deve ter como destino o porto de Santos (Tabela 1), sendo que toda a produção do centróide de Uberlândia deve ser escoada pelo seu terminal ferroviário, localizado na cidade de Araguari (MG), enquanto que toda a soja de Unaí e aproximadamente $64 \%$ dos grãos de Patrocínio deve ser deslocada com a combinação dos modais rodoviário e ferroviário para atingir o mesmo destino. Os outros centróides de Minas Gerais, como Uberaba, Araxá e parte da soja de Patrocínio, devem ter suas produções escoadas através das rodovias.

Tabela 1 - Quantidade de soja de Minas Gerais a ser despachada ao porto de Santos

\begin{tabular}{l|l|l|l}
\hline Centróide & Combinação/Modal & Quantidade $(\mathrm{t})$ & $\%$ \\
\hline \multirow{2}{*}{ Patrocínio } & Rodoviário & $186.814,00$ & $11,6 \%$ \\
\hline \multirow{2}{*}{ Uberaba } & Rodoviário & $57.644,78$ & $3,5 \%$ \\
\cline { 2 - 4 } & Rodo-ferroviário & $101.709,22$ & $6,3 \%$ \\
\hline Uberlândia & Rodoviário & $282.239,00$ & $17,5 \%$ \\
\hline Unaí & Ferroviário & $349.558,00$ & $21,7 \%$ \\
\hline Total & Rodo-ferroviário & $636.217,00$ & $39,4 \%$ \\
\hline
\end{tabular}

No estado de São Paulo, o total da produção de soja também deve ter como destino o porto de Santos (Tabela 2). Os centróides de Bauru, Araraquara e Campinas devem movimentar suas produções por meio do modal ferroviário e o escoamento da produção das regiões de São Joaquim da Barra, Limeira, Assis, Itapetininga, São José do Rio Preto, Araçatuba e Presidente Prudente, pelo modal rodoviário.

Tabela 2 - Quantidades de soja do Estado de São Paulo ao porto de Santos

\begin{tabular}{l|l|l|l}
\hline Centróide & Combinação/Modal & Quantidade (t) & $\%$ \\
\hline Araçatuba & Rodoviário & $47.650,00$ & $5,4 \%$ \\
\hline Araraquara & Ferroviário & $7.065,00$ & $0,8 \%$ \\
\hline Assis & Rodoviário & $257.144,00$ & $29,3 \%$ \\
\hline Bauru & Ferroviário & $40.704,00$ & $4,6 \%$ \\
\hline Campinas & Ferroviário & $11.581,00$ & $1,3 \%$ \\
\hline Itapetininga & Rodoviário & $239.570,00$ & $27,3 \%$ \\
\hline Limeira & Rodoviário & $5.033,00$ & $0,6 \%$ \\
\hline Presidente Prudente & Rodoviário & $41.104,00$ & $4,7 \%$ \\
\hline São Joaquim da Barra & Rodoviário & $206.555,00$ & $23,5 \%$ \\
\hline São José do Rio Preto & Rodoviário & $21.799,00$ & $2,5 \%$ \\
\hline Total & & $878.205,00$ & $100 \%$ \\
\hline
\end{tabular}

Parte da soja produzida na região sul do Mato Grosso também teve como destino indicado, o porto de Santos (Tabela 3). Para o total dos grãos produzidos em Cuiabá, a proposta apontada foi a combinação dos modais rodoviário, hidroviário e ferroviário para chegar ao porto em questão. O modal rodoviário foi indicado para o transporte até Santos de toda a produção de Alto Araguaia e 39\% da soja de Rondonópolis. O restante da soja do Mato Grosso, incluindo a dos centróides de Primavera do Leste, Sorriso, Nova Maringá e Campo Novo do Parecis, considerados na simulação matemática, não foi absorvido pelos portos apreciados neste trabalho, provavelmente devido à restrição de capacidade de exportação dos portos analisados no trimestre considerado. 
Tabela 3 - Quantidades de soja do Mato Grosso a serem despachadas ao porto de Santos

\begin{tabular}{l|l|l|l}
\hline Centróide & Combinação/Modal & Quantidade $(\mathrm{t})$ & $\%$ \\
\hline Alto Araguaia & Rodoviário & $229.319,00$ & $38,9 \%$ \\
\hline Cuiabá & Rodo-hidro-ferroviário & $78.688,00$ & $13,6 \%$ \\
\hline Rondonópolis & Rodoviário & $272.772,18$ & $47,5 \%$ \\
\hline Total & & $574.779,18$ & $100 \%$ \\
\hline
\end{tabular}

Ainda quanto ao Estado de Mato Grosso do Sul, a otimização do problema indicou que todos os grãos originários de Sonora e Cassilândia devem ser escoados através do modal rodoviário até o porto de Santos (Tabela 4). A soja de Campo Grande e Três Lagoas também deve ser totalmente destinada a Santos, porém exclusivamente por meio do modal ferroviário. O porto de Paranaguá (PR) foi apontado como destino da totalidade da produção da região de Iguatemi (MS) pelo modal rodoviário. O centróide de Dourados (MS) teve dois destino para a sua produção, mais de $72 \%$ ao porto de São Francisco do Sul (SC) e o restante ao porto de Paranaguá (PR) e, para ambos, os deslocamentos devem ser apenas através das rodovias.

Tabela 4 - Quantidades de soja do Mato Grosso do Sul a serem despachadas aos portos

\begin{tabular}{l|l|l|l|l}
\hline Centróide & Combinação/Modal & Porto & Quantidade $(\mathrm{t})$ & $\%$ \\
\hline Campo Grande & Ferroviário & Santos & $329.807,00$ & $13,3 \%$ \\
\hline Cassilândia & Rodoviário & Santos & $243.261,00$ & $9,8 \%$ \\
\hline \multirow{2}{*}{ Dourados } & \multirow{2}{*}{ Rodoviário } & Paranaguá & $373.481,93$ & $15,1 \%$ \\
\cline { 3 - 5 } & & S. Fco. Sul & $963.990,07$ & $38,9 \%$ \\
\hline \multirow{2}{*}{ gguatemi } & Rodoviário & Paranaguá & $178.836,00$ & $7,2 \%$ \\
\hline Sonora & Rodoviário & Santos & $348.684,00$ & $14,1 \%$ \\
\hline Três Lagoas & Ferroviário & Santos & $38.990,00$ & $1,6 \%$ \\
\hline Total & & & $2.477 .050,00$ & $100 \%$ \\
\hline
\end{tabular}

Os resultados da otimização apontaram que a soja produzida na região sul de Goiás deve ser integralmente destinada ao porto de Santos (Tabela 5).

Tabela 5 - Quantidades de soja do sul de Goiás a ser despachada ao porto de Santos

\begin{tabular}{l|l|l|l}
\hline Centróide & Combinação/Modal & Quantidade $(\mathrm{t})$ & $\%$ \\
\hline Catalão & Rodo-ferroviário & $402.145,00$ & $11,0 \%$ \\
\hline Goiânia & Rodo-ferroviário & $428.212,00$ & $11,7 \%$ \\
\hline Itumbiara & Rodo-ferroviário & $589.393,00$ & $16,1 \%$ \\
\hline Pires do Rio & Ferroviário & $305.575,00$ & $8,3 \%$ \\
\hline \multirow{2}{*}{ Rio Verde } & Rodoviário & $1.475 .328,62$ & $40,2 \%$ \\
\cline { 2 - 4 } & Rodo-hidro-ferroviário & $468.882,38$ & $12,7 \%$ \\
\hline \multirow{2}{*}{ Total } & & $3.669 .536,00$ & $100 \%$ \\
\hline
\end{tabular}

Sendo que a produção de Catalão, Itumbiara e Goiânia deve ser transportada por meio da combinação entre os modais rodoviário e ferroviário. Para o escoamento da produção de Pires do Rio a movimentação indicada é exclusivamente pelas ferrovias. A soja de Rio Verde deve ser deslocada através de duas alternativas, $75 \%$ via modal rodoviário, exclusivamente, e o remanescente via combinação rodovia, hidrovia e ferrovia.

A região que compreende o norte do Paraná tem mais de $42 \%$ de sua produção indicada para ser transportada apenas pelo modal rodoviário e com destino ao porto de Paranaguá (Tabela 6). São os centróides de: Wenceslau Braz, Ponta Grossa, Telêmaco Borba, Prudentópolis, Curitiba e Cascavel, que exportam todas as suas produções nesse modal, Goioerê, com 7\% da sua produção e Guarapuava com 67\%. O restante da soja de Guarapuava, bem como a totalidade de Maringá e 75\% de Londrina também tiveram como destino o porto de Paranaguá, porém apenas como alternativa o modal ferroviário. Ainda para Paranaguá foi apontada a totalidade da produção de Cornélio Procópio, 93\% de Goioerê e 52\% de Campo Mourão, contudo o transporte foi através da combinação entre rodovias e ferrovias. Como destino ao porto de São Francisco do Sul deve ser alocado $25 \%$ da soja de Londrina através 
do modal ferroviário, $48 \%$ de Campo Mourão por meio da combinação modal rodoviário e ferroviário, a totalidade produzida em Ivaiporã e $82 \%$ de Jacarezinho pelas rodovias apenas. O restante da soja de Jacarezinho teve como destino o porto de Santos por meio do modal rodoviário.

Tabela 6 - Quantidade de soja do norte do Paraná a ser despachada aos portos

\begin{tabular}{l|l|l|l|l}
\hline Centróide & Combinação/Modal & Porto & Quantidade $(\mathrm{t})$ & $\%$ \\
\hline \multirow{2}{*}{ Campo Mourão } & \multirow{2}{*}{ Rodo-ferroviário } & Paranaguá & $212.523,73$ & $6,8 \%$ \\
\cline { 3 - 5 } & & S. Fco Sul & $199.918,27$ & $6,4 \%$ \\
\hline Cascavel & Rodoviário & Paranaguá & $315.996,00$ & $10,1 \%$ \\
\hline \multirow{2}{*}{ Curitiba } & Rodo-ferroviário & Paranaguá & $185.014,00$ & $5,9 \%$ \\
\hline \multirow{2}{*}{ Goioerê } & Rodoviário & Paranaguá & $22.612,00$ & $0,7 \%$ \\
\hline \multirow{2}{*}{ Ivaiporapão } & Rodoviário & Paranaguá & $15.927,83$ & $0,6 \%$ \\
\cline { 2 - 5 } & Rodo-ferroviário & Paranaguá & $225.169,17$ & $7,2 \%$ \\
\hline \multirow{2}{*}{ Jacarezinho } & Rodoviário & Paranaguá & $173.162,75$ & $5,6 \%$ \\
\cline { 2 - 5 } & Ferroviário & Paranaguá & $85.679,25$ & $2,7 \%$ \\
\hline \multirow{2}{*}{ Londrina } & Rodoviário & S. Fco. Sul & $202.621,00$ & $6,5 \%$ \\
\hline Maringá & \multirow{2}{*}{ Rodoviário } & S. Fco. Sul & $30.046,89$ & $1,0 \%$ \\
\cline { 2 - 5 } & & Santos & $6.564,11$ & $0,2 \%$ \\
\hline Ponta Grossa & Ferroviário & Saranaguá & $253.415,75$ & $8,1 \%$ \\
\cline { 2 - 5 } & & S. Fco. Sul & $85.679,25$ & $2,7 \%$ \\
\hline Prudentópolis & Ferroviário & Paranaguá & $323.157,00$ & $10,4 \%$ \\
\hline Telêmaco Borba & Rodoviário & Paranaguá & $382.999,00$ & $12,3 \%$ \\
\hline Wenceslau Braz & Rodoviário & Paranaguá & $139.172,00$ & $4,5 \%$ \\
\hline Total & Rodoviário & Paranaguá & $64.605,00$ & $2,1 \%$ \\
\hline
\end{tabular}

Cabe observar a participação dos modais de transporte resultante da indicação do fluxo ótimo apontado pela solução do problema. Dos 12,33 milhões de toneladas exportadas no trimestre abril, maio e junho (base 2013), o resultado indica que a minimização global dos custos logísticos aponta, aproximadamente 6,97 milhões de toneladas sendo deslocadas para todos os três portos com o uso exclusivo de transporte rodoviário, 2,98 milhões de toneladas com o uso da combinação rodo-ferroviário, 0,55 milhões de toneladas com o uso da combinação de transporte rodo-hidro-ferroviário e 1,83 milhões de toneladas com o uso exclusivo do modal ferroviário.

Esses dados mostram que aproximadamente $57 \%$ de todo o volume exportado através dos portos chegam neles por uso exclusivo do transporte rodoviário e que $43 \%$ chegam com algum uso da alternativa ferroviária: combinado rodo-ferro, rodo-hidro-ferro e exclusivamente ferroviário. A participação referente à combinação rodo-hidro-ferroviário, surpreendentemente representa apenas 4,4\% das quantidades deslocadas. Estima-se que esse número insignificativo perante o conjunto de alternativas de deslocamento sofre a restrição da capacidade do trecho hidroviário devido ao período da seca, que no Centro-Oeste brasileiro exerce forte impacto no mês de junho, um dos meses do trimestre, indicando que o transporte hidroviário, ainda que tenha um custo variável mais barato do que todas as opções, possui forte restrição quanto à operacionalização do transporte de produtos que precisam ser deslocados no período de seca, particularmente devido às baixas dos rios que impedem as barcaças ou chatas de se movimentarem na sua capacidade máxima, chegando até à interrupção total das operações.

\section{CONSIDERAÇÕES FINAIS}

As quantidades de soja que deveriam ser deslocadas com o uso das diferentes alternativas modais, entre as regiões produtoras pertencentes ao Vetor Centro-Sudeste e os 
portos de Santos (SP), Paranaguá (PR) e São Francisco do Sul (SC), considerando a infraestrutura logística existente em 2012, para atingir o custo mínimo de transporte, no trimestre de abril, maio e junho, quando ocorre o pico das exportações foram resultados desse trabalho.

Na solução ótima, a totalidade da produção nas regiões do Triângulo Mineiro, sudoeste de Minas Gerais, sul de Goiás e o estado de São Paulo, bem como boa parte da soja da região sul do Mato Grosso e do estado do Mato Grosso do Sul devem ter suas exportações através do porto de Santos. O transporte rodoviário movimentaria $57 \%$ de toda a soja exportada no período analisado, devido à capacidade das ferrovias não ser suficiente para absorver as produções, e $43 \%$ chegarim aos portos com algum uso da alternativa ferroviária: rodo-ferroviária, rodo-hidro-ferroviária e exclusivamente ferroviária.

As vantagens proporcionadas pelas possibilidades intermodais são preferidas para a longa distância, a exemplo, o centróide de Cuiabá que através da combinação rodo-hidroferroviária, deveria escoar toda a sua produção para a exportação via Santos. Entretanto, a hidrovia, nos períodos de seca, tem sua capacidade reduzida e com isso, a alternativa de transporte mais cara, o transporte rodoviário, ou precisa ser contemplada, mesmo em distâncias significativas, ou a produção de certas regiões chega a ser preterida, por exemplo, Primavera do Leste (MT), que sequer participou da solução do problema.

A principal dificuldade encontrada foi a carência das informações sobre as capacidades específicas dos modais de transporte em determinada malha ferroviária ou hidroviária. A alternativa encontrada foi a utilização das quantidades de soja que chegaram aos portos no trimestre abril, maio e junho de 2013, segundo os modais possíveis. A programação linear e a linguagem GAMS mostraram ser eficientes recursos para a análise de redes logísticas e podem ser replicadas para simular alterações na rede tratada neste trabalho, bem com para a aplicação a outros problemas de fluxo.

Novas pesquisas correlatas podem considerar outros Vetores e portos, outras regiões produtoras e commodities, por exemplo, o milho, que vem ganhando significativos espaços comerciais no mercado internacional

\section{REFERÊNCIAS BIBLIOGRÁFICAS}

[1] AMARAL, M.; ALMEIDA, M. S.; MORABITO, R. Um modelo de fluxos e localização de terminais intermodais para escoamento da soja brasileira destinada à exportação. Revista Gestão \& Produção, v. 19, n. 2, p. 717-732, 2012.

[2] ANDRADE, E. L. Introdução à Pesquisa Operacional: métodos e modelos para a análise de decisões. 4. ed. Rio de Janeiro: LTC, 2009.

[3] ANTAQ. Indicadores do transporte de cargas: tonelada útil transportada (t) e tonelada quilômetro útil (tku). Agência Nacional de Transportes Aquaviários, 2012.

[4] ANTAQ. Relatório Técnico: Plano Nacional de Integração Hidroviária. Laboratório de Transportes e Logística da Universidade Federal de Santa Catarina, 2013.

[5] ANTAQ. Transporte de Cargas na Hidrovia do Paraná-Tietê 2010. Agência Nacional de Transportes Aquaviários, 2010.

[6] BAHIA, P. Q.; TOBIAS, M. S. G.; SOUZA, M. S.; SOUZA, M. G. A competitividade da soja do Centro-Oeste através da logística de redes de transportes de grãos de soja para exportação do estado do Mato-Grosso. In: XLV CONGRESSO DA SOCIEDADE BRASILEIRA DE ECONOMIA, ADMINISTRAÇÃO E SOCIOLOGIA RURAL, 2007, Londrina. Anais... Londrina: SOBER, 2007.

[7] BROOKE, A.; KENDRICK, D.; MEERAUS, A. GAMS: a user's guide. San Francisco: The Scientific Press, 1992. 
[8] CAIXETA FILHO, J. A. V. Pesquisa operacional: técnicas de otimização aplicadas a sistemas agroindustriais. 1. ed. São Paulo: Atlas, 2001.

[9] CASSUCE, F. C. C.; SANTOS, M. L. Desvalorizações cambiais e captação de divisas: o caso brasileiro de soja em grão. Revista Organizações Rurais e Agroindústrias. Lavras, v. 7, n. 3, p. 298-311, 2005.

[10] CNT. O sistema ferroviário brasileiro. Brasília: Confederação Nacional do Transporte, 2013.

[11] CNT. Pesquisa CNT de Ferrovias. Confederação Nacional do Transporte, 2011.

[12] CONAB. Acompanhamento de safra brasileira: grãos, quarto levantamento, janeiro 2015/ Companhia Nacional de Abastecimento. Brasília, 2015.

[13] DANTZIG, G. B.; Application of the simplex method to a transportation problem. Activy Analysis of Production and Allocation. Ed. T. C. Koopmans, p. 339-347, 1951.

[14] DEREX. Raio-X do comércio exterior brasileiro. Departamento de Relações Internacionais e Comércio Exterior. São Paulo, 2014.

[15] DNIT. Conheça a malha rodoviária federal. Disponível em: <http://www.dnit.gov.br/planejamento-e-pesquisa/planejamento/evolucao-da-malharodoviaria/snv2014-total.pdf/>. Acesso em: out./nov. 2014.

[16] EMBRAPA. Tecnologias de produção de soja - região central do Brasil 2008. Embrapa: Londrina, 2008.

[17] GOOGLE MAPS. Como chegar. Disponível em: <https://maps.google.com.br/>. Acesso em: out./nov. 2014.

[18] HILLIER, F. S.; LIEBERMAN, G. J.; Introdução à pesquisa operacional. 8. ed. São Paulo: McGraw-Hill, 2006.

[19] HIRAKURI, M. H.; LAZZAROTTO, J. J. Evolução e Perspectivas de Desempenho Econômico Associadas com a Produção de Soja nos Contextos Mundial e Brasileiro. Embrapa Soja. Londrina, 2011.

[20] IBGE. Produção Agrícola Municipal: culturas temporárias e permanentes 2012. Instituto Brasileiro de Geografia e Estatística. Rio de Janeiro, 2012.

[21] LAVORENTE, G. B. Caracterização das vias de exportação de soja do estado do Mato Grosso. Grupo de Pesquisa e Extensão em Logística Agroindustrial - ESALQ LOG. Piracicaba, 2011.

[22] MDIC. Quantidade exportada de soja mesmo triturada. Sistema de Análise das Informações de Comércio Exterior do Ministério do Desenvolvimento, Indústria e Comércio Exterior. Brasília, 2013.

[23] MINISTÉRIO DOS TRANSPORTES. Relatório executivo. Plano Nacional de Logística e Transportes - PNLT, 2007.

[24] OJIMA, A. L. R. O. Transporte de soja do estado do Mato Grosso para exportação. Revista de Economia Agrícola. São Paulo, v. 54, n. 1, p. 33-41, 2007.

[25] PEIXOTO, N. E. S.; PINTO, K. C. R. Rede de fluxo de custo mínimo para a soja destinada ao processamento no centro-sudeste brasileiro. Simpósio de Pesquisa Operacional e Logística da Marinha, 2012.

[26] PINHEIRO, M. A.; CAIXETA FILHO, J. V. O escoamento da soja em grão do Mato Grosso para exportação pelos portos de Santos, Paranaguá e Itaqui: Uma aplicação de 
programação linear. In: XLVIII CONGRESSO DA SOCIEDADE BRASILEIRA DE ECONOMIA, ADMINISTRAÇÃO E SOCIOLOGIA RURAL, 2010, Campo Grande. Anais... Campo Grande: SOBER, 2010.

[27] PINTO, K. C. R. Aprendendo a decidir com a pesquisa operacional: modelos e métodos de apoio à decisão. 1. ed. Uberlândia: EDUFU, 2005.

[28] PONTES, H. L. J.; CARMO, B. B. T.; PORTO, A. J. V. Problemas logísticos na exportação brasileira da soja em grão. Revista Eletrônica Sistemas \& Gestão, v. 4, n. 2, p. 155-181, mai./ago. 2009.

[29] REIS, J. D.; BRUNETTI, L.; CRUZ JÚNIOR, J. C.; ZILLI, J. B. Custo ótimo de transporte rodoviário das principais regiões produtoras de soja aos principais portos do Brasil. In: XLVI CONGRESSO DA SOCIEDADE BRASILEIRA DE ECONOMIA, ADMINISTRAÇÃO E SOCIOLOGIA RURAL, 2008, Rio Branco. Anais... Rio Branco: SOBER, 2008.

[30] ROSA, I. F.; MAKIYA, I. K. Sustentabilidade da soja brasileira no mercado internacional: gestão de trade off. In: VII CONGRESSO NACIONAL DE EXCELÊNCIA EM GESTÃO, 2011, Rio de Janeiro. Anais... Rio de Janeiro: CNEG, 2011.

[31] SILVA, M. P. S.; MARUJO, L. G. Análise de modelo intermodal para escoamento da produção da soja no centro oeste brasileiro. Journal of Transport Literature, v. 6, n. 3, p. 90-106, 2012. 